\title{
The impact of COVID-19 lockdown on physical activity and weight gain among active adult population in Israel: a cross- sectional study
}

Horesh Dor-Haim ${ }^{1 *}$ D, Sara Katzburg ${ }^{1,2}$, Polla Revach ${ }^{1}$, Hagai Levine ${ }^{3}$ and Sharon Barak ${ }^{4,5,6}$

\begin{abstract}
Background: The COVID-19 outbreak holds public health concerns. The stay-at-home increases sedentary behavior, with unintended adverse outcomes. Since organized recreation and sports facilities were closed, we aimed to study how the crisis of closure affected exercise habits and weight gain among the trainee population in Israel. We examined differences in weight gain among individuals with different PA activities and assessed their ability to adapt to digital media as an alternative training structure.

Methods: A cross-sectional survey consisted of a multiple-choice questionnaire obtained using a web-based survey application. Trainees (1202) who exercised steadily anonymously answered the questionnaire sent by their coaches regarding their activity and weight gain during lockdown times.

Results: Results confirmed that 70\% of Israelis trained less than their usual routine, $60 \%$ used digital media for training, 55\% gained weight. Half of the respondents gained more than $2 \mathrm{~kg}$, with an average increase of $1.2 \mathrm{~kg}$. However, those who exhibited a higher physical activity level gained less weight. Using digital media for training was associated with higher physical activity levels. The aged population was less likely to use digital media.

Conclusions: Since increased sedentary behavior could increase the risk for potential worsening of health conditions, health agencies should look for strategies, including digital remote media training to promote physical activity and subsequently, preventing the increased burden of future comorbidities worsening by a sedentary lifestyle. Approval: by the Helsinki ethics committee of Sheba Medical Center (6504-19-SMC).
\end{abstract}

Keywords: Physical activity, Exercise, Health status, Weight, Digital fitness modalities, Fitness applications

\footnotetext{
* Correspondence: horesh.dor-haim@mail.huji.ac.il

'O2 Health Promotion and Sports Medicine Department, The Howard and Mary Edith Cosell Association for Physical Education, the Safra sports center, Hebrew University, Givat Ram, Jerusalem, Israel

Full list of author information is available at the end of the article
}

(C) The Author(s). 2021 Open Access This article is licensed under a Creative Commons Attribution 4.0 International License, which permits use, sharing, adaptation, distribution and reproduction in any medium or format, as long as you give appropriate credit to the original author(s) and the source, provide a link to the Creative Commons licence, and indicate if changes were made. The images or other third party material in this article are included in the article's Creative Commons licence, unless indicated otherwise in a credit line to the material. If material is not included in the article's Creative Commons licence and your intended use is not permitted by statutory regulation or exceeds the permitted use, you will need to obtain permission directly from the copyright holder. To view a copy of this licence, visit http://creativecommons.org/licenses/by/4.0/. The Creative Commons Public Domain Dedication waiver (http://creativecommons.org/publicdomain/zero/1.0/) applies to the data made available in this article, unless otherwise stated in a credit line to the data. 


\section{Background}

The coronavirus disease 2019 (COVID-19) has an impact on physical activity (PA) behaviors worldwide. People around the world stayed at home self-isolated due to the lockdown policy [1]. Although the lockdown is essential and is the best recommendation for preventing the spread of the disease, it may create a new challenge. Staying at home for a prolonged period can lead to disturbing consequences such as weight gain, social isolation [2] and may also cause a reduction in PA levels $[2,3]$. The decrease in PA level may be especially apparent among active individuals habitually practicing sports. Diminished PA resulting from home isolation may worsen a wide range of health conditions, including the chronic ones, such as cardiac and metabolic diseases [25] as well as infectious diseases, due to negative immune-modulation [6-11] even without substantial weight gain [12, 13]. Therefore, maintaining an active lifestyle at home including mainly PA, is extremely important for the general populations' health, especially for people with additional risk factors including old adults during the quarantine [14-16].

According to the recommendation of the World Health Organization (WHO), the American College of Sports Medicine (ACSM) Position Stand, and PA guidelines for healthy adults, adults should do at least $150 \mathrm{~min}$ of moderate aerobic exercise or do at least $75 \mathrm{~min}$ of vigorous aerobic exercise during the week [16, 17]. This is in addition to muscle-strengthening activities, involving major muscle groups, for two or more days weekly [16, 18]. According to the Israeli National Health Interview Survey - INHIS 2013-2015 [19] only one-third of the Israeli population aged 21 and over complies with the WHOs' recommendations and walking being the sport of choice for most people [19]. As the consequence of physical inactivity is rising globally, WHO had developed a new Global Action Plan to promote PA in 2018-2030 [17]. However, with COVID-19 striking globally, adherence and devotion to PA is much more challenging, even for active individuals [20].

Longitudinal observational studies and experimental data identified determinants with strong causal associations to adherence to PA, such as characteristics of the person and their lifestyle habits, features of environments, and type of the activity itself [21, 22]. Markedly, socioeconomic status, education level, living arrangements, health status, physical fitness, and depression are factors that affect adherence, especially in old adults [23-25]. Improving adherence to PA, at times pandemics, can have a significant impact on longevity, quality of life, and health care costs in the long run [23]. Thus, it is essential to understand how the lockdown policy has affected PA behavior. Despite the barriers, it is crucial to maintain the regular regime of PA practiced on pre-pandemic days, to keep good mental and physical health [2]. Hence, it is worthwhile to study how to develop methods and strategies that allow remote PA among the regularly trained population.

Recent advances in mobile technology enable novel approaches to PA exercises using remote guidance and support. There is a wide range of at-home programs (videoor app-guided equipment-free), for aerobics or strength training. Studying the feasibility of at-home, web-based, interactive exercise programs [25] could enable researchers and health organizations to plan better strategies to encourage participants to engage in their PA.

We hypothesized that quarantine and closure of organized exercise installations would impair trainees' exercise and habits, alter the daily caloric balance and lead to weight gain. Studies around the world showed a negative impact on physical activity during COVID-19 closure [26-29]. Therefore, the current study aimed to study the effects of lockdown policy on Israeli trainees' PA level and exercising habits, analyze the association between these habits and weight gain, and evaluate the adaptability of the trainees to home-based digital technologies to maintain a healthy lifestyle during COVID19 pandemics.

\section{Methods}

The cross-sectional survey (convenience sampling) examined the PA of participants (n-1202) during MarchApril 2020 (May 20 to May 10). participants answered anonymously a questionnaire that consisted of multiplechoice questions (ST1). The questionnaire was developed for the study and was not used or published before. The questionnaire included information relating to demographics and exercise habits, before and during quarantine, medical status (ST1). Determination of the sample size done by an a priori power analysis showing that for multiple regression analysis (F test) with small effect size ( $\mathrm{f} 2=0.02$ ), $\alpha$ err probability $=0.05$, and maximum four predictors, the total sample size required for achieving actual power of 0.80 is $n=602$. For one-way analysis of variance ( $\mathrm{F}$ test), with a small effect size ( $\mathrm{f}=$ 0.10 ), $\alpha$ err probability $=0.05$, and five groups, the total sample size required for achieving actual power of 0.80 is $n=1200$, using G*Power 3.0.10 for Power analysis calculations. The survey was obtained using the IMKFORMS, conducted web-based survey application.

The IMKFORMS system is optimized for mobile phones, collecting information from the respondents and export it into an Excel file (ST2). The survey was delivered via WhatsApp groups of trainers, targeting their trainees who were exercising in classes, gyms, and community centers. The trainers had no access to the database. Approval for the study by the Helsinki ethics 
committee of Sheba Medical Center (6504-19-SMC). All participants gave written informed consent.

\section{Data analysis}

Description of demographics, PA, and training characteristics, were calculated using descriptive statistics (mean, median, range, and 95\% confidence of interval) and chi-squared tests (ST1). Examination of the associations between age, PA level, and health status factors was done using Spearman rank correlations. Based on weight gain status participants, were divided into two groups (no weight gain vs. weight gain). Between-group differences in PA frequency were compared, by using the Mann-Whitney $U$ test. For the evaluation of PA frequency, participants were subdivided into four groups according to their weekly PA frequency $(0,1,2,3$ days /week (. Between-group differences in health status were done using the MannWhitney U test. Participant's intention to return to the previous PA level, based on their health status, was compared using the Kruskal-Wallis test and Conover posthoc test. Evaluation of age differences among individuals within each PA frequency group was done using the one-way analysis of variance with TukeyKramer post-test for all pairwise comparisons was done. For factors predicting PA frequency and weight gain, "two forward stepwise multiple linear regression" was done (ST3-ST4). Only variables having significant correlations with the dependent variables and matched the study's hypothesis were included [ST2, ST3). For multicollinearity, independent variables were examined using the variance of inflation factor > 10 [30]. The alpha level for inclusion criteria was 0.05 , the alpha level for exclusion was 0.10 . The coefficient of reliability (or consistency), of the questionnaire, was measured using Cronbach's alpha [31]. Using Little's MCAR test showed that data were not missing "at random". However, to avoid biased parameter estimates, a complete case analysis [32], was done and individual missing data were excluded.

Table 1 Physical activity characteristics

\begin{tabular}{|c|c|c|c|}
\hline Physical activity characteristic & & $\mathrm{n}$ & $\%$ \\
\hline \multirow[t]{5}{*}{ Organized physical activity* $(n=1202)$} & In a team or an organized group & 439 & $36.52 \%$ \\
\hline & Fitness room & 306 & $25.45 \%$ \\
\hline & Personal training & 42 & $3.49 \%$ \\
\hline & More than one organized activity & 313 & $26.03 \%$ \\
\hline & Not in an organized activity & 102 & $8.48 \%$ \\
\hline \multirow[t]{4}{*}{ Current physical activity level vs. before Corona* $(n=1202)$} & Similar level & 185 & $15.39 \%$ \\
\hline & Less active & 270 & $22.46 \%$ \\
\hline & Significantly less active & 578 & $48.08 \%$ \\
\hline & More active & 169 & $14.05 \%$ \\
\hline \multirow[t]{6}{*}{ Home digital physical activity modalities* $(n=1202)$} & Not used & 265 & $22.04 \%$ \\
\hline & I tried but it wasn't good for me & 256 & $21.29 \%$ \\
\hline & Movies in the internet/TV & 196 & $16.30 \%$ \\
\hline & Programs like Zoom & 285 & $23.71 \%$ \\
\hline & Training applications & 54 & $4.49 \%$ \\
\hline & Several digital training modalities & 146 & $12.14 \%$ \\
\hline \multirow[t]{5}{*}{ Intention to return to previous physical activity* types $(n=1198)$} & No - afraid of the virus & 75 & $6.30 \%$ \\
\hline & Not decided & 73 & $6.10 \%$ \\
\hline & Yes, considering activity will be in accordance with the regulations & 430 & $35.90 \%$ \\
\hline & Yes, immediately & 618 & $51.50 \%$ \\
\hline & No, my health deteriorated in the last month & 2 & $0.20 \%$ \\
\hline \multirow[t]{5}{*}{ Physical activity frequency* $(n=1202)$} & $0 /$ week & 113 & $9.40 \%$ \\
\hline & $1 /$ week & 172 & $14.30 \%$ \\
\hline & 2/ week & 225 & $18.71 \%$ \\
\hline & 3/ week & 245 & $20.38 \%$ \\
\hline & 4 / week or more & 447 & $37.18 \%$ \\
\hline
\end{tabular}




\section{Results}

1202 adults participated in the study. Age range: $18-85$ years $(48.52+15.60$ Old adults defined as $>65$ years old, $(n=227) .75 .0 \%$ (901) females and 25\% (301) males (chisquared $=299.50, p<0.001)$. The questionnaire's Cronbach's was acceptable $($ Cronbach alpha $=0.70)$.

\section{Physical activity and exercising characteristics}

Twenty-five percent of participants exercised in the fitness room $3.49 \%$ exercised with a personal coach, participating in more than one organized activity (26.03\%), or not $(8.48 \%)$. About one-third exercised as part of a team or in organized PA groups (36.52\% of the sample; chi-squared $=439.75, p<0.01$ ). Seventy percent reported that they exercised less than usual, while $63 \%$ (less active $22.46 \%$; significantly less active $48.08 \%$, chisquared $=355.15, p<0.001$ ), Table 1 ) reported that in the past month they exercised three times a week or less. Half of the participants (51.50\%) reported that they intend to return to PA activities as soon as the restrictions end or when PA will be allowed by the regulations (35.90\%). Only $0.20 \%$ of the participants informed about health status in the past months and therefore have no intention of returning to their previous PA types. 6.30\% reported they were afraid to return to their previous PA types, and $6.10 \%$ have not decided whether or not to return to their previous PA regimes (chi-squared $=736.10$, $p<0.001)$.

$37.18 \%$ of the participants reported exercising 4 times/ week as compared to $20.38 \%$ (3 times/week), $18.71 \%$ (2 times/week), $14.30 \%$ (1 day a week) and $9.40 \%$ who did not practice at all (chi-squared $=262.23, p<0.01$ ). The median physical activity was 3 times/week (Table 1 )

\section{Health status of the participants}

Overall, $87.3 \%$ reported to be in good health, $11.3 \%$ reported having good health in conjunction with chronic diseases, and $1.3 \%$ were suffering from chronic diseases and disability (chi-squared $=1614.12, p<0.001$ ). Regarding weight gain, $45.2 \%$ did not gain weight, $16.2 \%$ gained $1 \mathrm{Kg}, 18.8 \%$ gained $2 \mathrm{KG}, 11.2 \%$ gained $3 \mathrm{Kg}, 8.6 \%$ gained $4 \mathrm{Kg}$ or more (chi-squared $=1181.14, \mathrm{p}<0.001)$. The median weight gain was $1 \mathrm{~kg}$ (Table 2).

\section{Associations between age, physical activity, and health parameters}

Significant positive correlations between age and health status were observed $(r=0.229, p<0.0001)$. Significant positive correlations between Weight gain and PA frequency $(\mathrm{r}=-0.38, p<0.001, \mathrm{r}$ ranges from -0.080 to $0.229 ; \mathrm{p}<0.05)$ and usage of home digital physical activity modalities $(r=-0.111, p<0.001)$ was noticed. PA frequency was significantly positive correlated with usage of home digital PA modalities $(r=0.295, p<0.001$; Table 2).

In comparison to participants gaining weight, participants who did not gain weight were significantly more physically active $(P<0.001$, the median number of PA days $=2$ vs. 4 , respectively; Fig. 1).

Compared to individuals with chronic diseases or chronic diseases with disabilities, individuals with good health had a significantly higher intention to immediately return to their previous PA level $(\mathrm{P}<0.001$, Fig. 2$)$

No age-related differences were observed in the different categories to return to previous PA types. Similarly, no significant between-group differences were found, in the various health status groups with PA frequency (Fig. 3)

Participants who conducted PA $>4 /$ week $(n=446)$, were significantly older than participants who practiced

Table 2 Associations between age, physical activity, and health parameters

\begin{tabular}{|c|c|c|c|c|c|c|}
\hline & & Age & $\begin{array}{l}\text { Health } \\
\text { Status }\end{array}$ & Weight gain & $\begin{array}{l}\text { physical } \\
\text { activity frequency }\end{array}$ & $\begin{array}{l}\text { Home digital physical } \\
\text { activity modalities }\end{array}$ \\
\hline \multirow[t]{3}{*}{ Age } & r & - & 0.229 & -0.080 & 0.094 & -0.033 \\
\hline & $p$ & - & $<0.001^{*}$ & $0.006^{*}$ & $0.001^{*}$ & 0.258 \\
\hline & $\mathrm{n}$ & - & 1175 & 1178 & 1175 & 1178 \\
\hline \multirow[t]{3}{*}{ Health status } & r & - & - & -0.002 & -0.031 & -0.052 \\
\hline & $p$ & - & - & 0.952 & 0.283 & 0.072 \\
\hline & $\mathrm{n}$ & - & - & 1202 & 1202 & 1202 \\
\hline \multirow[t]{3}{*}{ Weight gain } & r & - & - & - & -0.382 & -0.111 \\
\hline & $p$ & - & - & - & $<0.001^{*}$ & $<0.001^{*}$ \\
\hline & $\mathrm{n}$ & - & - & - & 1202 & 1202 \\
\hline \multirow{3}{*}{$\begin{array}{l}\text { physical } \\
\text { activity frequency }\end{array}$} & r & - & - & - & - & 0.295 \\
\hline & $\mathrm{p}$ & - & - & - & - & $<0.001^{*}$ \\
\hline & $n$ & - & - & - & - & 1202 \\
\hline
\end{tabular}




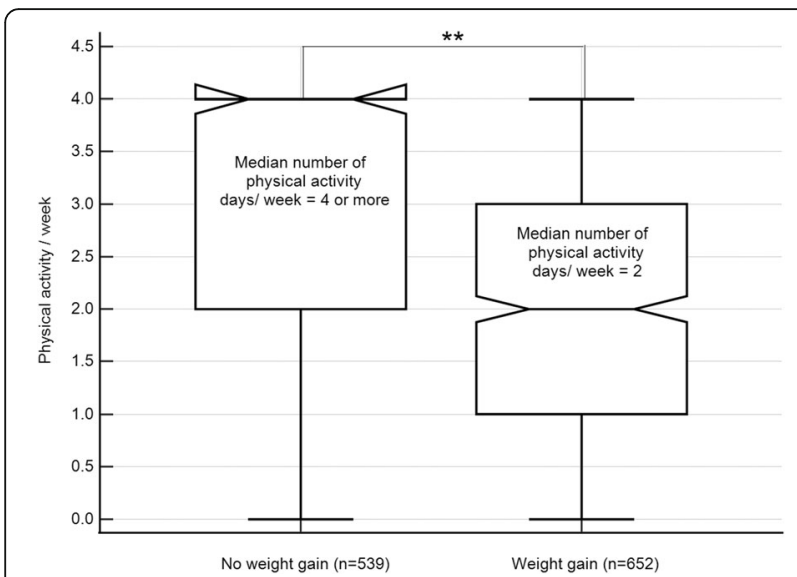

Fig. 1 Physical activity level based on weight gain group. ${ }^{*}$ Significant between-group differences at $p<0.01$ (Mann-Whitney $\mathrm{U}$ test $=109,800.00$ ); The central box represents the values from the lower to upper quartile ( 25 to 75 percentile); the vertical line extends from the minimum to the maximum value; the middle line represents the median

PA less than 4/week ( $n=756 ; \mathrm{F}=4.14, p \leq 0.002$; Fig. 3 ). However, comparing the participants who were physically active (conducting PA $>3 /$ week), there were no significant between-group differences concerning their health status (good health, 61.90\%; good health with chronic diseases, 65.69\%; and chronic diseases with a disability, 62.50\%). Multiple regression analysis showed

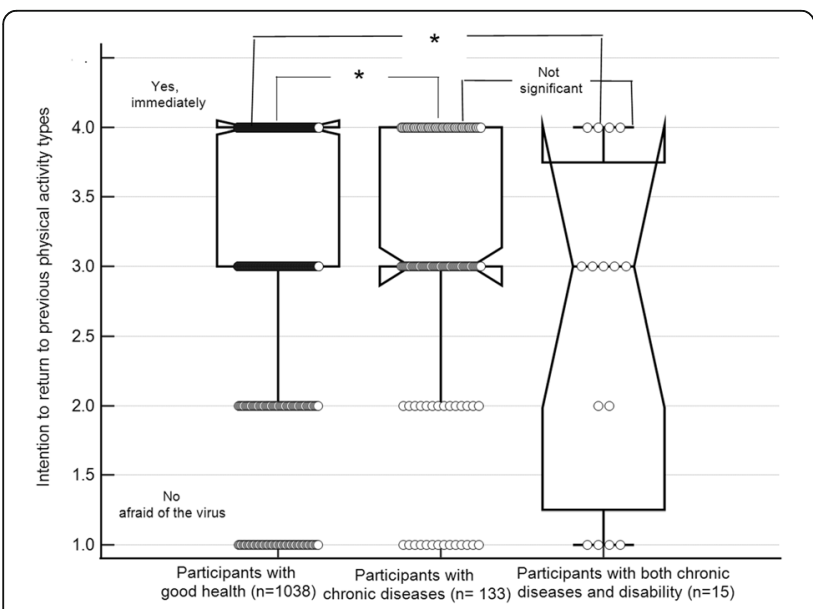

Fig. 2 Return to physical activity intentions based on health status. Significant at $p<0.05$ (Conover post-hoc test); Intention to return to physical activity category 5 ( - no, because my health deteriorated), was omitted from the analysis as it included only two participants; the central box represents the values from the lower to upper quartile ( 25 to 75 percentile); the vertical line extends from the minimum to the maximum value, excluding outside values which are displayed as separate points. An outside value is defined as a value that is smaller than the lower quartile minus 1.5 times the interquartile range, or larger than the upper quartile plus 1.5 times the interquartile range; the middle line represents the median

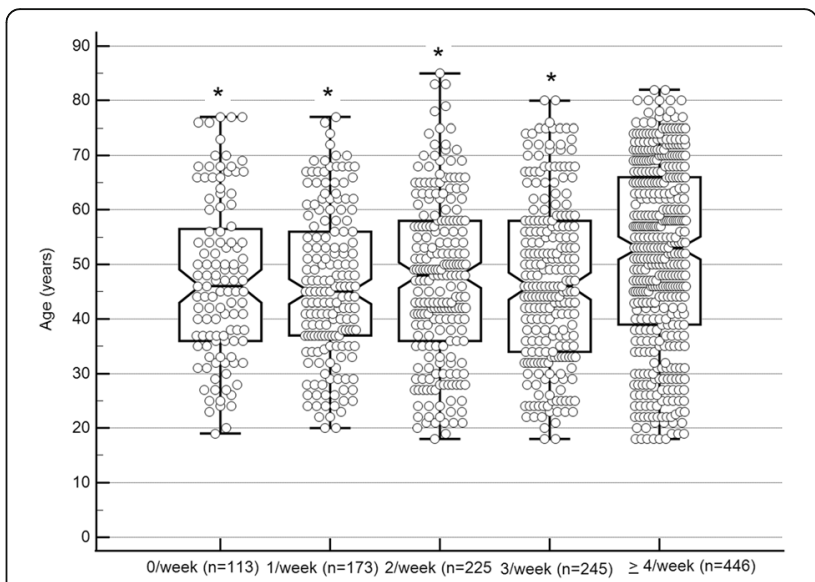

Fig. 3 Physical activity frequency - age differences. * significantly different than 4/week group at $p<0.05$ (Tukey-Kramer test for all pairwise comparisons); the central box represents the values from the lower to upper quartile (25 to 75 percentile); the vertical line extends from the minimum to the maximum value, excluding outside values which are displayed as separate points. An outside value is defined as a value that is smaller than the lower quartile minus 1.5 times the interquartile range, or larger than the upper quartile plus 1.5 times the interquartile range; the middle line represents the median

that older age and the greater usage of home physical activity modalities predicted greater frequency of PA level (adjusted $\mathrm{R} 2=0.10 ; \mathrm{F}$ ratio $=69.51 ; p<0.001$ ). However, only reduced PA frequency significantly predicted weight gain (adjusted R2 $=0.156 ; \mathrm{F}$ ratio $=71.05$; $\mathrm{p}<0.001$ ). For additional information (Table 3).

\section{Discussion}

Our study shows that PA level significantly decreased during the COVID-19 lockdown. Of the participants, $70 \%$ reported that they exercised less than usual, while 63\% (Table 1) reported exercising 3 times a week or less, and correlated to increased weight gain (54.8\%). PA level correlated with the usage of home digital PA modalities (Tables 2 and 3).

The current study reveals the negative effect of lockdown and social distancing policy on PA level and exercising habits and health status among physically active adults during COVID-19. We assume that the closure resulted in a reduction in PA below the minimum recommendations of health organizations which is in line with other studies that showed a decline in PA level during closure times $[2,9,15,26,27,29]$. The study suggests that pandemics such as the current pandemic [1], pose unique health issues caused by the requirements to stay at home, leading to a reduction in PA, among all people and especially among physically active individuals habitually practicing sports [33]. Although lockdown may be essential to mitigate the pandemic, it also generates new health challenges. Staying at home for a 
Table 3 Prediction of physical activity level and weight

\begin{tabular}{|c|c|c|c|c|c|}
\hline Dependent variables & Independent variables & B Coefficient & Standard error & t & $\mathrm{p}$ \\
\hline \multirow[t]{4}{*}{ Last month physical activity frequency } & (Constant) & 1.40 & & & \\
\hline & Age & 0.007 & 0.002 & 3.42 & $<0.001$ \\
\hline & $\begin{array}{l}\text { Usage of home digital physical } \\
\text { activity modalities }\end{array}$ & 0.26 & 0.022 & 11.36 & $<0.001$ \\
\hline & \multicolumn{5}{|c|}{$\mathbf{R}^{\mathbf{2}}=0.10 ;$ Adjusted $\mathbf{R}^{\mathbf{2}}=0.10 ; \mathbf{F}$ ratio $=69.51 ; \boldsymbol{P}<0.001$} \\
\hline \multirow[t]{5}{*}{ Weight gain } & (Constant) & 2.469 & & & \\
\hline & Age & -0.004 & 0.002 & -1.949 & 0.051 \\
\hline & Physical activity frequency & -0.385 & 0.028 & -13.357 & $<0.001$ \\
\hline & $\begin{array}{l}\text { Usage of home digital physical } \\
\text { activity modalities }\end{array}$ & -0.008 & 0.024 & -0.353 & 0.723 \\
\hline & \multicolumn{5}{|c|}{$\mathbf{R}^{2}=0.158 ;$ Adjusted $\mathbf{R}^{2}=0.156 ; \mathbf{F}$ ratio $=71.05 ; \boldsymbol{P}<0.0001$} \\
\hline
\end{tabular}

Notes: continuous variables: included are only variables that had significant correlations with the dependent variables. Categorical variables: only variables that differed significantly in the dependent variables, were included; the Variance inflation factor in all analyses was $<10$

prolonged time may increase sedentary habit $[2,3]$ and decrease PA level $[12,34]$ that may lead to disturbing consequences such as an increased risk of worsening health conditions (including chronic ones) [2, 3], weight gain $[12,34]$ insufficient sunlight exposure, social isolation [2] and can affect metabolic health [35]. While regular exercise has a positive impact on mental health and overall mood [36], prolonged stay at home can lead to inactivity and contribute to anxiety and depression, which leads to an even more sedentary lifestyle and weight gain [9, 26, 37-39]. Altogether, sedentary behavior and low levels of physical activity can have adverse effects on well-being and quality of life.

The Israeli Ministry of Health closed all organized activities in mid-March, including gyms and fitness centers [40]. The Government enforced restrictions upon outdoor and recreational activities and limited outdoor and social activities to a maximal radius of $100 \mathrm{~m}$ distant from home. Whereas the blockade policy aimed to prevent the spread of COVID-19, there was no reference or guidance on maintaining normal PA levels during times of social distancing and isolation, regardless of the health implications that could result from physical inactivity. Thus, our survey exhibited the difficulty of maintaining a healthy and active lifestyle during the lockdown. Seventy percent of the participants, who were physically active in their daily life before the pandemic broke, indicated a significant decrease in the PA level related to increased weight gain. A correlation between age, health status, and the reduced PA level was found. The population with poor health status was the most prone to pandemic quarantine. They were less likely to initiate homebased activities. Their health toll is higher as a sequel of physical inactivity and can lead to deterioration of their health condition. In the old-adult population, there was a positive association between age and the frequency of physical activity. They were less likely to engage in digital home-based physical activity but had proficient and regular training habits that did not change even in time of closure. This surprising result may reflect the relative resilience of the aged healthy trained population, striving not to neglect their lifestyle habits. For the less active older adult population, the situation is different and should be further studied. Cardiovascular deconditioning might increase the risk for cardiovascular disease as deconditioning of the musculoskeletal system might increase frailty, Osteoporosis, and risk of falling among the elderly $[41,42]$.

Physical inactivity and a sedentary lifestyle are risk factors for coronary vascular disease, diabetes, and many more non-communicable diseases (NCDs). Although the general activity of the old adult group is limited, a priory, nevertheless, this population is the most vulnerable to high morbidity caused by COVID-19 [43-45]. Up to 40 million individuals die each year from NCDs, $20-30 \%$ of these cases related to a deficiency in PA [46]. The total volume of accumulated sedentary time in prolonged, uninterrupted bouts is also associated with allcauses of mortality. Therefore, any PA guidelines should aim to reduce the sedentary time to avoid the risk of death $[47,48]$.

Lifestyles and PA have been changed globally during the coronavirus pandemic lockdown [2, 33, 49]. Data collected by Fitbit wristwatches from over 30 million active users around the world showed a decrease in PA of $38 \%$ in Spain, a $14 \%$ decrease in North America, and a $24 \%$ decrease in Israel [50]. Garmin users reported a massive decline in the overall number of steps taken during the second 2 weeks of March [51]. Therefore, it is essential to grant access to activity substitutes, especially for old adults, to keep them fit and healthy at their own homes. However, the ability of people to change to a new, unaccustomed regime that uses digital technology and social media is limited. It is necessary to make 
digital technology effective and accessible for all people, particularly for those with special needs. Furthermore, there is a need to implement and improve digital technology to enable a better attitude toward digital technology. Such technologies can help introduce a broader range of PA and media solutions, focusing on different populations, communities, languages, and cultures. By utilizing digital technology, it is possible to deliver content designed for remote PA exercise at home when regular training options are unavailable.

The current survey found that $55 \%$ of the participants gained weight during the March-April pandemic quarantine. Weight gain was significantly correlated negatively with age, PA level, and use of home digital PA modalities. However, a multiple regression analysis showed that only a reduction in PA level significantly predicted weight gain. Weight gain and metabolic syndrome are a global crucial public health issue concerning sedentary behavior, during the recent COVID-19 pandemic $[52,53]$. The syndrome is related to increased weight gain, abdominal obesity, hypertriglyceridemia, low high-density lipoprotein cholesterol, high blood pressure, and hyperglycemia [52, 54]. People having metabolic syndrome are at increased risk of developing diabetes and cardiovascular disease [54]. According to the Israeli Central Bureau of Statistics, $48 \%$ of adults are overweight [55]. The study surveyed overall active individuals $(57 \%$ of study participants were performing PA at least three times a week), with a considerable average increase in weight $(1.25 \mathrm{~kg})$. However, participants who conducted PA $>4$ times/week did not gain weight. The weighted mean weight regained with or without exercise training was only 0.28 and $0.33 \mathrm{~kg} / \mathrm{month}$, respectively. Based on observational studies, an actual increase in energy expenditure of PA of approximately $6300-8400 \mathrm{~kJ} /$ week $(1500-2000 \mathrm{kcal} /$ week $)$ is associated with improved weight maintenance [56]. The increased weight gain outcome in the active individuals, adherence is explained by the decrease in non-exercise activity thermogenesis (NEAT) that is the energy expenditure of all physical activities other than volitional sporting-like exercise. Since activity levels declined, it is not surprising that the whole NEAT decreased substantially, reflecting the increased indoor inactivity time. To bring it back to the former state there is a need to develop strategies by reengineering our home environments [57]. Exercise is also associated with long-term weight loss through the relationship of its associated psychological changes, together with improved nutrition, than through direct effects of energy expenditures, which are typically minimal in deconditioned individuals. There is a mutual relationship between exercise and diet [58-60]. Exercise can induce changes in mood, body image, self-efficacy, selfesteem and improves eating habits and weight loss [58,
60]. Likewise, diet and dietary practices affect mental well-being [59] Engaging in healthy behaviors leads to increased motivation for the enhancement of well-being and improvement of mental health.

That mutual effect has a better impact than the direct effects of energy expenditures that are typically minimal in deconditioned individuals $[13,61,62]$. Weight gain is associated not only with PA level but also with nutrition. COVID-19 has influenced people eating habits. Preliminary data from the Brookdale Institute survey in Israel showed changes in nutritional routine during the home lockdown, wherein people were reporting consuming more food, more sweets, and snacks [35].

The current survey showed PA behavioral changes among the trainee population. Even though participants have had more spare time to exercise, they had numerous difficulties maintaining their PA routine. This effect of the pandemic health crisis on a person's well-trained behavior is paradoxical. Hypothetically, a person who routinely exercises has acquired a "toolbox" filled with skills and training habits. Naturally, we would expect him/her to preserve and use his/her skills while in urgent need. Paradoxically the study shows that most participants reduced their PA level, and only $15 \%$ increased their PA. One explanation for this aforementioned paradoxical effect might be related to stress. More specifically, the stressful situation caused by the pandemic might have brought difficulties in maintaining an active lifestyle. Another possible explanation for the observed reduction in the PA level might be related to differences in adherence to individualized and group exercise. At times of closure, there is no option to use the existing infrastructure for PA in residential areas such as parks and fitness clubs as Israel had closed all recreation and sports facilities. Therefore, the ability to exercise with others was limited. Exercising with others was associated with superior adherence behavior [63]. Adults exposed to a team-building activity intervention reported greater adherence than those who participated in a standardcare program [64]. An alternative to the group activity might be engaging in PA with digital technology. Appropriate adaptation to the changed situation allowed participants to maintain their active routine even during the lockdown.

However, that adjustment was age-dependent, and older adults found it hard to adopt digital technology as an alternative to organized PA [65, 66]. For an active adult population, the consequences of inactivity and improper diet will be visible long after the crisis is over. It may result in an increased burden of NCDs, increased risk for morbidity due to metabolic, cardiovascular disease, and muscular deconditioning. Thus, the various governmental institutions and health agencies need to consider how to prevent it. An emergency plan must be 
built, within the health promotion actions to include specific policies and guidelines for home-based physical training. We hence encourage the various governmental institutions and health organizations to consist clear instructions for PA in nationwide lockdowns, allowing a safe performance of outdoor PAs (walking, running, or other individual sports) and thus prevent any future pandemic from generating unfavorable consequences that should arise due to acute cessation of physical activity. Furthermore, it might be advisable to engage in community-wide campaigns that deliver messages regarding upholding the PA level during lockdown by using the media such as television, radio, and newspaper columns. The surveyed group was different from the general population. This group was used to train regularly, acquired good healthy habits before the covid-19 pandemic, and thus were more motivated to adhere. Presumably, the general population was even worse at the time of the closure. This study was subject to several methodological limitations. The majority of the participants who responded to the survey were women, the generalizability of this study may be limited mainly to overall active females. Participants had to report the number of days per week in which they practiced PA > 20 min rather than depict the actual time and intensity. Therefore, there is no certainty as to whether they followed the WHO guidelines. Besides, this crosssectional study refers to reports on PA level and weight. Future studies should incorporate objective measures (e.g., accelerometry and weight measurements). Finally, the data presented in this study represents a snapshot of the current situation relevant to the early stages of the pandemic in Israel. As the pandemic evolves and subsequent national and institutional new policies and practices developed and implemented, future follow-up investigations will be necessary to understand the effects of COVID-19 over time.

\section{Conclusion}

In conclusion, this study showed a negative effect of lockdown and social distancing policy on PA levels and weight gain. However, those who exhibited higher PA levels gained less weight. Using digital media for training was associated with a higher PA level. Therefore, there is a need for governmental and health agencies to rethink a health policy in which PA will be more accessible during pandemic crises, especially for the aged population and people with special physical and medical needs. Outdoor or home-based remote training using Digital technology can be a suitable substitute for gym-based installations. $51 \%$ of survey participants, including aged and those with medical risk factors, reported their intention to go back to their original organized activity. About $10 \%$ were concerned about returning to their pre- pandemic exercise regime. These concerns illustrate the importance of organized PA in peoples' lives as an essential need for their physical, social, and mental health. All this should be taken into consideration when organized activity is closed.

\section{Abbreviations}

PA: physical activity; ACSM: American College of Sports Medicine; WHO: World Health Organization; NCD's: non-communicable diseases

\section{Supplementary Information}

The online version contains supplementary material available at https://doi. org/10.1186/s12889-021-11523-z.

Additional file 1. ST1 The multiple-choice questionnaires.

Additional file 2. ST2 Raw collecting data.

Additional file 3. ST3 Regression physical activity level.

Additional file 4. ST4 Regression weight gain.

\section{Acknowledgments}

Not applicable.

Authors' contributions

$\mathrm{HDH}$ - Initiator and designer of the research and methods, writing. SK Scientific writing and editing. PR - Conducting the survey and writing. HL Writing and scientific consulting. SB - Statistical and Data Analysis, writing. All authors have read and approved the manuscript.

Funding

No financial support was received for this work.

Availability of data and materials

Is included as supplements: ST1-ST4.

\section{Declarations}

Ethics approval and consent to participate

The study was approved by the Helsinki ethics committee of Sheba Medical Center (6504-9-SMC). All participants gave written informed consent.

Consent for publication

Not applicable.

Competing interests

None of the authors have any potential, perceived, or real conflict of interest.

\section{Author details}

${ }^{1} \mathrm{O} 2$ Health Promotion and Sports Medicine Department, The Howard and Mary Edith Cosell Association for Physical Education, the Safra sports center, Hebrew University, Givat Ram, Jerusalem, Israel. ${ }^{2}$ Department of

Developmental Biology and Cancer Research, Israel-Canada Medical Research Institute, Faculty of Medicine, Hebrew University of Jerusalem, Jerusalem, Israel. ${ }^{3}$ Braun School of Public Health and Community Medicine, Hebrew University of Jerusalem, Jerusalem, Israel. ${ }^{4}$ The Edmond and Lily Safra Children's Hospital, Department of Pediatric Rehabilitation, The Chaim Sheba Medical Center, Ramat-Gan, Israel. ${ }^{5}$ Kaye Academic College of Education, Beer-Sheva, Israel. ${ }^{6}$ College of Public Health Ben-Gurion University of the Negev, Beer-Sheva, Israel.

Received: 19 November 2020 Accepted: 19 July 2021

Published online: 06 August 2021

References

1. TEAM WHO. Coronavirus disease 2019 (COVID-19) situation report - 37 2020: World Healh Organization; 2020. 
2. Balanzá-Martínez V, Atienza-Carbonell B, Kapczinski F, De Boni RB. Lifestyle behaviours during the COVID-19 - time to connect. Acta Psychiatr Scand. 2020;141(5):399-400. https://doi.org/10.1111/acps.13177.

3. Vandelanotte C, Sugiyama T, Gardiner P, Owen N. Associations of leisuretime internet and computer use with overweight and obesity, physical activity and sedentary behaviors: cross-sectional study. J Med Internet Res. 2009;11(3):e28. https://doi.org/10.2196/jmir.1084.

4. Lippi G, Henry BM, Sanchis-Gomar F. Physical inactivity and cardiovascular disease at the time of coronavirus disease 2019 (COVID-19). Eur J Prev Cardiol. 2020:27(9):906-8. https://doi.org/10.1177/2047487320916823.

5. Bélair MA, Kohen DE, Kingsbury M, Colman I. Relationship between leisure time physical activity, sedentary behaviour and symptoms of depression and anxiety: evidence from a population-based sample of Canadian adolescents. BMJ Open. 2018;8(10):e021119. https://doi.org/10.1136/ bmjopen-2017-021119.

6. Maier HE, Lopez R, Sanchez N, Ng S, Gresh L, Ojeda S, et al. Obesity increases the duration of influenza a virus shedding in adults. J Infect Dis. 2018;218(9):1378-82. https://doi.org/10.1093/infdis/jiy370.

7. Codella R, Luzi L, Inverardi L, Ricordi C. The anti-inflammatory effects of exercise in the syndromic thread of diabetes and autoimmunity. Eur Rev Med Pharmacol Sci. 2015;19(19):3709-22.

8. Krause Mda S, de Bittencourt PI Jr. Type 1 diabetes: can exercise impair the autoimmune event? The L-arginine/glutamine coupling hypothesis. Cell Biochem Funct. 2008;26(4):406-33. https://doi.org/10.1002/cbf.1470.

9. Chen P, Mao L, Nassis GP, Harmer P, Ainsworth BE, Li F. Coronavirus disease (COVID-19): the need to maintain regular physical activity while taking precautions. J Sport Health Sci. 2020;9(2):103-4. https://doi.org/10.1016/j. jshs.2020.02.001.

10. Nieman DC, Wentz LM. The compelling link between physical activity and the body's defense system. J Sport Health Sci. 2019;8(3):201-17. https://doi. org/10.1016/j.jshs.2018.09.009.

11. Warren KJ, Olson MM, Thompson NJ, Cahill ML, Wyatt TA, Yoon KJ, et al. Exercise improves host response to influenza viral infection in obese and non-obese mice through different mechanisms. PLoS One. 2015;10(6): e0129713. https://doi.org/10.1371/journal.pone.0129713.

12. Luzi L, Radaelli MG. Influenza and obesity: its odd relationship and the lessons for COVID-19 pandemic. Acta Diabetol. 2020;57(6):759-64. https:// doi.org/10.1007/s00592-020-01522-8.

13. González-Gross M, Meléndez A. Sedentarism, active lifestyle and sport: impact on health and obesity prevention. Nutr Hosp. 2013;28(Suppl 5):89-98.

14. Anderson E, Durstine JL. Physical activity, exercise, and chronic diseases: a brief review. Sports Med Health Sci. 2019;1(1):3-10. https://doi.org/10.1016/j. smhs.2019.08.006.

15. Lippi G, Henry BM, Bovo C, Sanchis-Gomar F. Health risks and potential remedies during prolonged lockdowns for coronavirus disease 2019 (COVID19). Diagnosis. 2020;7(2):85-90. https://doi.org/10.1515/dx-2020-0041.

16. team WHO. Global Strategy on Diet, Physical Activity and Health. On-Line: World Health Organization; 2011

17. Organization WH. Global action plan on physical activity 2018-2030: more active people for a healthier world: World Health Organization; 2018.

18. Arena R, Myers J, Williams MA, Gulati M, Kligfield P, Balady GJ, et al. Assessment of functional capacity in clinical and research settings: a scientific statement from the American Heart Association Committee on exercise, rehabilitation, and prevention of the council on clinical cardiology and the council on cardiovascular nursing. Circulation. 2007;116(3):329-43. https://doi.org/10.1161/CIRCULATIONAHA.106.184461.

19. Israel National Health Interview Survey NHIS-3 2013-2015 [Online]. In: Israel MoHSo, editor. Jerusalem: Ministry of Health State of Israel; 2016.

20. Kohl HW 3rd, Craig CL, Lambert EV, Inoue S, Alkandari JR, Leetongin G, et al. The pandemic of physical inactivity: global action for public health. Lancet 2012;380(9838):294-305. https://doi.org/10.1016/S0140-6736(12)60898-8.

21. Bauman AE, Sallis JF, Dzewaltowski DA, Owen N. Toward a better understanding of the influences on physical activity: the role of determinants, correlates, causal variables, mediators, moderators, and confounders. Am J Prev Med. 2002;23(2):5-14. https://doi.org/10.1016/S074 9-3797(02)00469-5.

22. Dishman RK, Sallis JF, Orenstein DR. The determinants of physical activity and exercise. Public Health Rep. 1985;100(2):158.

23. Rivera-Torres S, Fahey TD, Rivera MA. Adherence to exercise programs in older adults: informative report. Gerontol Geriatric Med. 2019:5: 2333721418823604.
24. Jiménez-Pavón D, Carbonell-Baeza A, Lavie CJ. Physical exercise as therapy to fight against the mental and physical consequences of COVID-19 quarantine: special focus in older people. Prog Cardiovasc Dis. 2020;63(3): 386-8. https://doi.org/10.1016/j.pcad.2020.03.009.

25. Feng NC, Ryan E, Kidane M, Tusch ES, McFeeley BM, Carlsson R, et al. Feasibility of an at-home, web-based, interactive exercise program for older adults. Alzheimers Dement. 2019;5(1):825-33. https://doi.org/10.1016/j.trci.2 019.10.005.

26. López-Bueno R, Calatayud J, Andersen LL, Balsalobre-Fernández C, Casaña J, Casajús JA, et al. Immediate impact of the COVID-19 confinement on physical activity levels in Spanish adults. Sustainability. 2020;12(14):5708. https://doi.org/10.3390/su12145708.

27. Hargreaves EA, Lee C, Jenkins M, Calverley JR, Hodge K, Houge MS. Changes in physical activity pre-, during and post-lockdown COVID-19 restrictions in New Zealand and the explanatory role of daily hassles. Front Psychol. 2021; 12:410.

28. Robinson E, Boyland E, Chisholm A, Harrold J, Maloney NG, Marty L, et al. Obesity, eating behavior and physical activity during COVID-19 lockdown: a study of UK adults. Appetite. 2021;156:104853. https://doi.org/10.1016/j.a ppet.2020.104853

29. Puccinelli PJ, da Costa TS, Seffrin A, de Lira CAB, Vancini RL, Nikolaidis PT, et al. Reduced level of physical activity during COVID-19 pandemic is associated with depression and anxiety levels: an internet-based survey. BMC Public Health. 2021;21(1):1-11.

30. Myers $\mathrm{RH}$, Myers $\mathrm{RH}$. Classical and modern regression with applications. Belmont: Duxbury press; 1990.

31. Cortina JM. What is coefficient alpha? An examination of theory and applications. J Appl Psychol. 1993;78(1):98-104. https://doi.org/10.1037/ 0021-9010.78.1.98

32. Jakobsen JC, Gluud C, Wetterslev J, Winkel P. When and how should multiple imputation be used for handling missing data in randomised clinical trials-a practical guide with flowcharts. BMC Med Res Methodol. 2017;17(1):1-10

33. Ravalli S, Musumeci G. Coronavirus outbreak in Italy: physiological benefits of home-based exercise during pandemic: Multidisciplinary Digital Publishing Institute; 2020.

34. Kumanyika SK, Obarzanek E, Stettler N, Bell R, Field AE, Fortmann SP, et al. Population-based prevention of obesity: the need for comprehensive promotion of healthful eating, physical activity, and energy balance: a scientific statement from American Heart Association Council on epidemiology and prevention, interdisciplinary Committee for Prevention (formerly the expert panel on population and prevention science). Circulation. 2008;1 18(4):428-64. https://doi.org/10.1161/CIRCULATIONAHA.108.189702.

35. Michal Laron RG. Health Behaviors during the COVID-19 Pandemic Preliminary Findings. 2020. https://brookdale.jdc.org.il/en/publication/israelihousehold-health-behaviors-corona/.

36. Fox KR. The influence of physical activity on mental well-being. Public Health Nutr. 1999;2(3a):411-8. https://doi.org/10.1017/S1368980099000567.

37. Robinson TN, Matheson D, Wilson DM, Weintraub DL, Banda JA, McClain A, et al. A community-based, multi-level, multi-setting, multi-component intervention to reduce weight gain among low socioeconomic status Latinx children with overweight or obesity: the Stanford GOALS randomised controlled trial. Lancet Diabet Endocrinol. 2021;9(6):336-49. https://doi.org/1 $0.1016 / S 2213-8587(21) 00084-X$

38. Chtourou H, Trabelsi K, H'mida C, Boukhris O, Glenn JM, Brach M, et al. Staying physically active during the quarantine and self-isolation period for controlling and mitigating the COVID-19 pandemic: a systematic overview of the literature. Front Psychol. 2020;11. https://doi.org/10.3389/fpsyg.2020.01708.

39. Maugeri G, Castrogiovanni P, Battaglia G, Pippi R, D'Agata V, Palma A, et al. The impact of physical activity on psychological health during Covid-19 pandemic in Italy. Heliyon. 2020;6(6):e04315. https://doi.org/10.1016/j. heliyon.2020.e04315.

40. Israel MoCaSGo. Guidelines regarding sports activities in the corona era. Ministry of Culture and Sports Goverment of Israel; 2020. https://www.gov.il/ he/departments/general/guidelines_sports_activities_corona.

41. Sherrington C, Lord S, Finch CF. Physical activity interventions to prevent falls among older people: update of the evidence. J Sci Med Sport. 2004; 7(1):43-51. https://doi.org/10.1016/S1440-2440(04)80277-9.

42. Gregg EW, Pereira MA, Caspersen CJ. Physical activity, falls, and fractures among older adults: a review of the epidemiologic evidence. J Am Geriatr Soc. 2000;48(8):883-93. https://doi.org/10.1111/j.1532-5415.2000.tb06884.x. 
43. Zhou F, Yu T, Du R, Fan G, Liu Y, Liu Z, et al. Clinical course and risk factors for mortality of adult inpatients with COVID-19 in Wuhan, China: a retrospective cohort study. Lancet. 2020;395(10229):1054-62. https://doi. org/10.1016/50140-6736(20)30566-3.

44. Zheng Z, Peng F, Xu B, Zhao J, Liu H, Peng J, et al. Risk factors of critical \& mortal COVID-19 cases: a systematic literature review and meta-analysis. J Inf Secur. 2020;81(2):e16-25. https://doi.org/10.1016/j.jinf.2020.04.021.

45. Jordan RE, Adab P, Cheng K. Covid-19: risk factors for severe disease and death: British Medical Journal Publishing Group; 2020

46. Organization WH. Noncommunicable diseases and their risk factors. STEPwise approach to noncommunicable disease risk factor surveillance (STEPS). Accessed 18 Mar 2018.

47. Diaz KM, Howard VJ, Hutto B, Colabianchi N, Vena JE, Safford MM, et al. Patterns of sedentary behavior and mortality in US middle-aged and older adults: a national cohort study. Ann Intern Med. 2017;167(7):465-75. https:// doi.org/10.7326/M17-0212.

48. Vancampfort D, Stubbs B, Koyanagi A. Physical chronic conditions, multimorbidity and sedentary behavior amongst middle-aged and older adults in six low-and middle-income countries. Int J Behav Nutr Phys Act. 2017;14(1):1-13.

49. Fallon K. Exercise in the time of COVID-19. Aust J Gen Pract. 2020;49(Suppl 13): $1-2$.

50. STAFF F. The Impact of Coronavirus on Physical Activity All Over the World 2020.

51. Garmin. Garmin blog [Internet]. Garmin, editor. Garmin; 2020. https://www. garmin.com/en-US/blog/general/the-effect-of-the-global-pandemic-on-a ctive-lifestyles/\#: : text=For\%20further\%20clarity\%2C\%20the\%20results,in\%2 Oweekend\%20activity\%20suddenly\%20disappeared.

52. Ford E, Giles W, Dietz W. Prevalence of the Metabolic Syndrome Among US Adults. JAMA. 2002;287(3):356. [cited 2018 Oct 10].

53. Zaki N, Alashwal H, Ibrahim S. Association of hypertension, diabetes, stroke, cancer, kidney disease, and high-cholesterol with COVID-19 disease severity and fatality: a systematic review. Diabet Metabol Syndrome. 2020;14(5): 1133-42. https://doi.org/10.1016/j.dsx.2020.07.005.

54. O'Neill S, O'Driscoll L. Metabolic syndrome: a closer look at the growing epidemic and its associated pathologies. Obes Rev. 2015;16(1):1-12. https:// doi.org/10.1111/obr.12229.

55. only D. Obesity report: About half of the population in Israel is in a state of overweight or obesity. Association of Public Health Physicians in Israel; 2018. https://publichealth.doctorsonly.co.il/2018/09/148469/.

56. Fogelholm M, Kukkonen-Harjula K. Does physical activity prevent weight gain-a systematic review. Obes Rev. 2000;1(2):95-111. https://doi.org/10.104 6/j.1467-789x.2000.00016.x.

57. Levine JA, Vander Weg MW, Hill JO, Klesges RC. Non-exercise activity thermogenesis: the crouching tiger hidden dragon of societal weight gain Arterioscler Thromb Vasc Biol. 2006;26(4):729-36. https://doi.org/10.1161/ 01.ATV.0000205848.83210.73.

58. Annesi JJ, Johnson PH, McEwen KL. Changes in self-efficacy for exercise and improved nutrition fostered by increased self-regulation among adults with obesity. J Prim Prev. 2015;36(5):311-21. https://doi.org/10.1007/s10935-0150398-z.

59. Begdache L, Chaar M, Sabounchi N, Kianmehr H. Assessment of dietary factors, dietary practices and exercise on mental distress in young adults versus matured adults: a cross-sectional study. Nutr Neurosci. 2019;22(7): 488-98. https://doi.org/10.1080/1028415X.2017.1411875.

60. Annesi JJ, Tennant GA. Generalization of theory-based predictions for improved nutrition to adults with morbid obesity: implications of initiating exercise. Int J Clin Health Psychol. 2014;14(1):1-8. https://doi.org/10.1016/S1 697-2600(14)70031-6.

61. Kjønniksen L, Anderssen N, Wold B. Organized youth sport as a predictor of physical activity in adulthood. Scand J Med Sci Sports. 2009;19(5):646-54. https://doi.org/10.1111/j.1600-0838.2008.00850.x.

62. Swift DL, Johannsen NM, Lavie CJ, Earnest CP, Church TS. The role of exercise and physical activity in weight loss and maintenance. Prog Cardiovasc Dis. 2014;56(4):441-7. https://doi.org/10.1016/j.pcad.2013.09.012.

63. Burke SM, Carron AV, Shapcott KM. Cohesion in exercise groups: an overview. Int Rev Sport Exerc Psychol. 2008;1 (2):107-23. https://doi.org/10.1 080/17509840802227065.

64. Bruner MW, Spink KS. The effects of team building on the adherence patterns of youth exercise participants. J Sport Exerc Psychol. 2007:29.
65. Seger J. The new digital [st] age: barriers to the adoption and adaptation of new technologies to deliver extension programming and how to address them. J Ext. 2011;49(1):37996-0343.

66. Chester MV, Allenby B. Toward adaptive infrastructure: flexibility and agility in a non-stationarity age. Sust Resilient Infrastr. 2019;4(4):173-91. https://doi. org/10.1080/23789689.2017.1416846.

\section{Publisher's Note}

Springer Nature remains neutral with regard to jurisdictional claims in published maps and institutional affiliations.
Ready to submit your research? Choose BMC and benefit from:

- fast, convenient online submission

- thorough peer review by experienced researchers in your field

- rapid publication on acceptance

- support for research data, including large and complex data types

- gold Open Access which fosters wider collaboration and increased citations

- maximum visibility for your research: over $100 \mathrm{M}$ website views per year

At BMC, research is always in progress.

Learn more biomedcentral.com/submissions 